\section{Supportive study climate and academic performance among university students: the role of psychological capital, positive emotions and study engagement}

Terje Slåtten, Gudbrand Lien, Solveig Beyza Narli Evenstad and Terje Onshus

Inland School of Business and Social Sciences, Inland Norway University of Applied Sciences - Lillehammer Campus, Lillehammer, Norway

\begin{abstract}
Purpose - The overall aim of this study is to explore factors associated with academic performance among university students. Specifically, it explores whether a supportive study climate is directly related to academic performance and whether students' psychological capital (PsyCap), positive emotions and study engagement play a role in the relationship between supportive study climate and academic performance.

Design/methodology/approach - A total of 588 bachelor students from a range of academic programs participated in a survey. The partial least squares (PLS)-based structural equation modeling (SEM) was used to test the conceptual models and the hypothesized relationships, using the software SmartPLS.

Findings - No support was found for a direct relationship between supportive study climate and academic performance. However, the results show that PsyCap, positive emotions and study engagement have a mediating role between supportive study climate and academic performance. In addition, the findings reveal a multifaceted pattern among PsyCap, positive emotions and study engagement that promotes academic performance.

Originality/value - This is the first study that simultaneously explores the role of PsyCap, emotions and study engagement between supportive study climate and academic performance among university students. Consequently, it broadens and deepens previous research and offers both theoretical and practical implications.
\end{abstract}

Keywords Psychological Capital, Positive emotions, Study engagement, Academic performance, Supportive study climate, University students

Paper type Research paper

\section{Introduction}

An important parameter of interest for higher education institutions - some would say the most critical parameter - is the level of academic performance of the students. OrtegaMaldonado and Salanova (2018) label academic performance "one of the most relevant

(C) Terje Slåtten, Gudbrand Lien, Solveig Beyza Narli Evenstad and Terje Onshus. Published by Emerald Publishing Limited. This article is published under the Creative Commons Attribution (CC BY 4.0) licence. Anyone may reproduce, distribute, translate and create derivative works of this article (for both commercial and non-commercial purposes), subject to full attribution to the original publication and authors. The full terms of this licence may be seen at: http://creativecommons.org/licences/by/4.0/legalcode
Supportive study climate and academic performance

Received 26 March 2020 Revised 1 May 2020 Accepted 1 May 2020 
IJQSS

13,4

outcomes in the university setting" (p. 390). Following this line of reasoning, there is a parallel between educational institutions and business organizations because both are most often interested in the level of performance of their workers and focus on how to maintain and/or increase this performance. Consequently, if one considers being a student as "work" (Salanova et al., 2010) and "work duties" (Datu et al., 2018), it becomes imperative to identify both individual and constellations of factors that have the potential to influence the academic performance of students. As Ortega-Maldonado and Salanova (2018) argue: "research [...] is necessary to develop evidence-based interventions to improve students' performance and learning” (p. 390).

A concept suggested to be positively associated with students' academic performance is the relatively new notion of psychological capital, PsyCap, which focuses on the positive personal resources a person possesses. Research has revealed that PsyCap is linked to academic performance (Carmona-Halty et al., 2018; Ortega-Maldonado and Salanova, 2018; Vanno et al., 2014). However, because PsyCap is a new concept, there is a need for significantly more research into several aspects of PsyCap, such as how and in what way PsyCap is linked to academic performance. Datu et al. (2018) note that the role of PsyCap has been given "limited attention" (p. 260). In a similar vein, CarmonaHalty et al. (2018) comment that PsyCap "has [only] begun to be assessed in education settings" (p. 3). Clearly, there is a need for more research into the role of students' PsyCap in academic performance.

There has been a call for more research into what role social factors in an academic setting might play for students' PsyCap and their academic performance. However, to our knowledge, only one previous study has explored this relationship (refer to a study of Carmona-Halty et al., 2019). In their study Carmona-Halty et al. (2019) found that the linkages within teacher-student relationships (representing the social factors in an academic setting) were directly related to students' PsyCap. Moreover, it was also revealed that PsyCap fully mediates the association between teacher-student relationships and academic performance. Clearly, these findings indicate that PsyCap plays an important role in academic performance. However, the study of CarmonaHalty et al. (2019) has two limitations, which serve to motivate the present study. First, in their study, the sample only consisted of adolescent high school students 1218 years of age. The authors suggested that future research "could include different academic levels [...] e.g. undergraduate university students" (Carmona-Halty et al., 2019, p. 4). We follow this suggestion and focus on university students in our sample. Second, as noted, the social factors in Carmona-Halty et al. (2019) were limited to only studying the impact of teacher-student relationships. However, the authors recommended that future research should incorporate other social factors "in order to obtain a better understanding of the role of significant others in academic PsyCap" (Carmona-Halty et al., 2019, p. 4). We therefore examine the impact of social factors in an academic setting more broadly, with a specific focus on students' perception of whether there is a supportive study climate at their university.

Based on the abovementioned knowledge gap in the literature, this paper focuses on the direct role of PsyCap in relation to academic performance. It also embraces several other factors that might be indirectly associated with PsyCap and enablers of academic performance. Thus, the aims of the study can be summarized as follows:

- to examine factors associated with academic performance among university students;

- to explore whether a supportive study climate is directly related to academic performance; and 
- to explore the role that students' PsyCap, positive emotions, and study engagement play in the relationship between supportive study climate and academic performance.

This study broadens and deepens previous research on academic performance in numerous ways and offers both theoretical and practical implications for higher education institutions.

The paper is structured as follows. First, the conceptual framework is explained. Second, the literature is reviewed, clarifying the content of different concepts and linkages in the study climate and academic performance conceptual framework. Third, the research methodology and findings from the empirical study are outlined. The paper closes with a discussion of contributions and conclusions that can be drawn from this study.

\section{Conceptual framework}

The conceptual framework of this study is visualized in Figure 1. The framework is organized into three separate parts, labeled as Input-Process-Output (IPO). Each part of the IPO is related in a causal manner.

The Output part of the framework is represented by the study-related outcome variable and the overall core aim and focus variable of this study that is academic performance. The Input part is represented by the environmental factor labeled as supportive study climate. The Process part (marked with a dashed line) embraces a total of three components of mind, specifically PsyCap, positive emotions and study engagement. The three components of mind are internally linked and simultaneously related to both the input-and-output variable. As seen in Figure 1, supportive study climate is suggested to have two main paths for how it influences students' academic performance. The first path is where a supportive study climate is directly related to academic performance. The second path is where the relationship between supportive study climate and academic performance is mediated by the three components of mind. In the following, the links in Figure 1 are discussed.

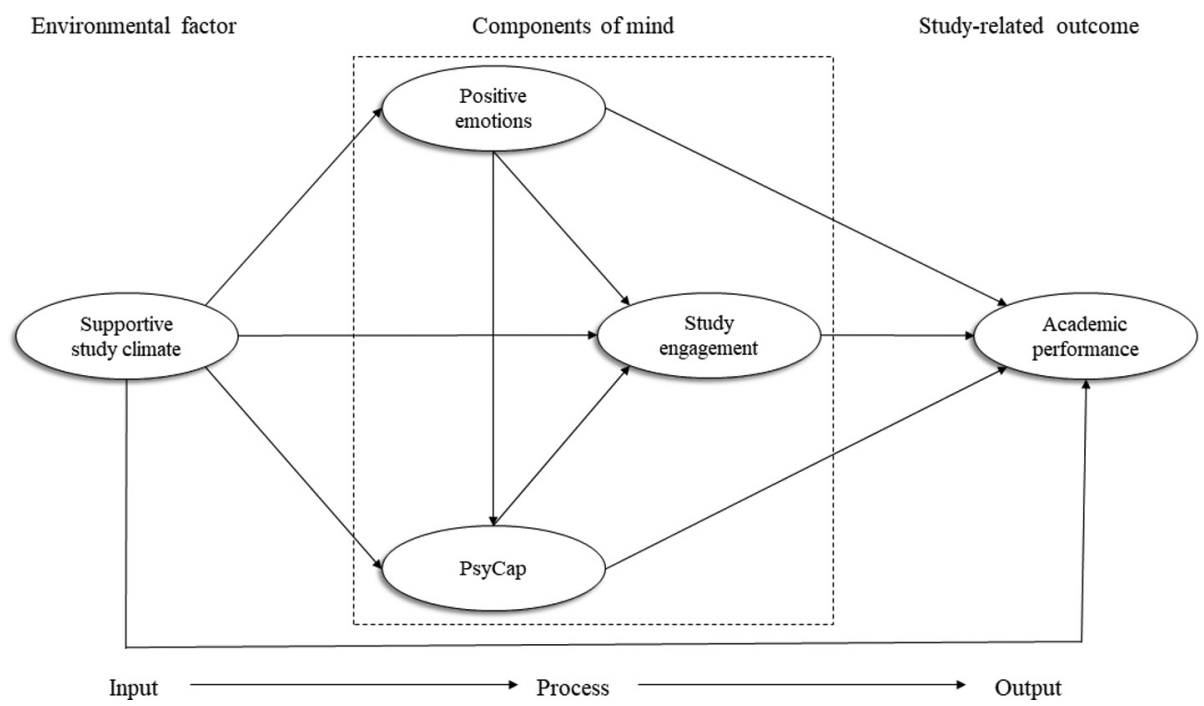

Figure 1. Conceptual framework 
IJQSS

13,4

\section{Review of literature and hypotheses}

Supportive study climate and academic performance

It is important "to motivate students to obtain high levels in academic performance" (Ortega-Maldonado and Salanova, 2018, p. 390). Academic performance is a core variable and "one of the most relevant outcomes" (Ortega-Maldonado and Salanova, 2018, p. 390). Academic performance could be studied as achievement related to parameters such as the level of theoretical knowledge and practical skills. However, this study makes no distinction between academic performance domains but defines and studies it as the overall grade point average of students' achievement. This definition is in line with previous research (OrtegaMaldonado and Salanova, 2018; Vanno et al., 2014).

To be a student is comparable with "work" (Salanova et al., 2010) and "work duties" (Datu et al., 2018) in organizations in a more traditional sense. Consequently, it becomes essential to create and maintain a work climate that most effectively and positively promotes the performance of workers in the organization. Based on this reasoning, in this study, the idea of students' work climate as a predictor of students' academic performance is considered. In the literature, work climate is characterized as an individual person's perceptions and surface experience of an organization (Zhou and Shalley, 2008). Consequently, the concept of work climate in its original nature is a broad concept and there is a need to narrow it to capture and focus on aspects of work climate that are both relevant and specific for what a person actually experiences and perceives. With this in mind, the concept of work climate in this study is limited to only climatic conditions relevant for students' daily "work" and consequently limited to the sphere of being a student and is labeled as supportive study climate. Specifically, supportive study climate is defined and refers to students' experience and perception of such aspects as helpfulness and support from lecturers, peer students and support resources offered by the university. As seen in Figure 1, supportive study climate is suggested as an environmental factor.

It is reasonable to assume that a supportive study climate is linked to students' academic performance. Within organizational research, it is well documented that a supportive climate is a predictor for employees' performance. Luthans et al. (2008) stress the importance of this relationship by stating: "supportive contexts are needed [...] to achieve sustainable growth and performance" (p. 224). Furthermore, the authors underscore the criticality of supportive climate by declaring: "one key component of employees' performance is the amount of support they receive" (p. 224). In addition, research within an educational context indicates that support from teachers and peers is a predictor of performance-related variables and outcomes such as students' academic motivation (Wentzel et al., 2010). The linkage between supportive study climate and academic performance is also supported by social capital theory. Social capital is about "who you know" (Luthans et al., 2004, p. 46) and indicates potential access to valuable resources for a person based on social relationships. When a student experiences or perceives a positive supportive study climate at their university it means implicitly having access to support resources, referring to help and support from peer students, lecturers and the administrative system. Consequently, having access to this constellation of support resources should contribute positively to achieving a better academic performance compared with those students who perceive less access to these support resources. The preceding discussion brings us to these hypotheses:

H1. The higher the degree of supportive study climate, the greater the academic performance will be. 
Role of components of mind in promoting academic performance

Figure 1 refers to three components of mind, that is, positive emotions, study engagement and PsyCap. These components have two aspects in common. First, they all reflect overall components that traditionally have been studied and are central within psychology, that is affect, conation and cognition (Huitt and Cain, 2005). Second, each component of mind is suggested to be a part of processes having a mediating role between the input (referring to the supportive study climate as an environmental factor) and the output (referring to the academic performance as a study-related outcome) in Figure 1. The content and role of each component are elaborated in detail in the following.

Positive emotions. Positive emotions in Figure 1 is an affect component of mind. According to Huitt and Cain (2005), affect refers to such aspects as "emotional interpretation of perceptions, information, or knowledge" (p. 1). Affect embraces a different set of mental responses ranging from emotions at one end, through moods in the middle and evaluations at the other end (Peter and Olson, 1996). Compared with the mental responses, moods and evaluations are emotions "characterized by the highest level of psychological arousal and intensity” (Slåtten, 2011, p. 27). To capture psychological arousal and intensity of positive emotions in this study, two aspects are considered. First, positive emotion is based on the definition of emotions by Lazarus (1991) who defined emotions as a "reflection of a person's appraisal of their environment." In this study, it refers to a student's positive emotions of being a student and reflected in diverse types of arousal-strength levels of positive emotions such as positive feelings, happiness, joy and satisfaction. Second, to capture the occurrence and duration of positive emotions, regarding time, students reported how often they experienced the different types of arousal-strength levels of positive emotions. This latter aspect is important because it broadens the concept of positive emotions from not only being just a short, only "in-the-moment" and a state-like construct to reflect a person's experience of relatively long-term duration of positive emotions. Consequently, such positive emotions capture more stable tendencies of having positive emotions. Accordingly, this makes the concept of positive emotions (relatively) comparable to a personality trait-like construct.

Positive emotions are always triggered by someone or something. Fredrickson (2001) supports this stating: "an emotion begins with an individual's assessment of the personal meaning of some antecedent event" (p. 218). Consequently, there is an input or antecedent(s) that releases positive emotions. In this study, the input to positive emotions is an environmental factor and specifically refers to students' experience or perception of a supportive study climate at their university. This linkage is based on the cognitive perspective of emotions (Fineman (2003) for details). It promotes that emotions are a result of how a person evaluates their environment. Consequently, the more students experience and perceive help and support from their lecturers, peer students and the administrative system at their university the more arousal and intensity in positive emotions students should experience. An increase in positive emotions would also, in the next round, promote an increase in academic performance. The latter linkage is based on positive psychology. Specifically, it finds support within a broaden-and-build theory of positive emotions (Fredrickson, 2001). This theory proposes that "positive emotions broaden [a person's] attention and cognition" (Fredrickson and Joiner, 2002, p. 172). Attention and cognition are both essential ingredients in the learning process. Consequently, because positive emotions broaden and expand students' attention and cognition for learning it is reasonable to assume that this would potentially lead to a positive increase in academic performance. In contrast, if students have a lower level of positive emotions or negative emotions it would limit their attention and cognition for learning and thus lead to decreased academic performance. This latter assumption is supported by previous research. For example, in their study,
Supportive study climate and academic performance

589 
IJQSS

13,4

Villavicencio and Bernardo (2013) found that negative emotions had a negative moderating effect on students' academic achievement or performance. However, this study limited its focus to (only) explore the role of positive emotions. In line with the aims of positive psychology, it seeks to "understand [.. . ] factors that allow individuals [...] to flourish" (p. 218). Based on the abovementioned discussion, it is assumed that when students experience positive emotions, because of favorable experiences and perceptions of a supportive study climate at university, this leads to an increase in the academic performance of students. Consequently, positive emotions are assumed to be a mediator between supportive study climate and academic performance. Hence, the following hypothesis is proposed:

H2. Positive emotions mediate the relationship between supportive study climate and academic performance.

Study engagement. Study engagement in Figure 1 is a conative component of mind. Conation is the "personal, intentional, planful, deliberate, goal-oriented, or striving component of motivation, the proactive [. . . ] aspect of behavior" (Huitt and Cain, 2005, p. 1). Moreover, Atman (1987) termed conation as "vectored energy; i.e. personal energy that has both direction and magnitude" (p. 15). In line with these thoughts, study engagement is directed and embraces students' levels of personal energy with one's "work" of being a student. Consequently, study engagement is about students' enthusiasm or study-focused effort and their "psychological connection with their work" (Bakker et al., 2011, p. 4) and reflect a "work-related state of mind" (Schaufeli et al., 2002a, 2002b, p. 74). Specifically, the concept of study engagement embraces three dimensions: absorption, dedication and vigor (Bakker et al., 2008; Schaufeli et al., 2002a, 2002b). The first dimension, absorption, captures student's levels of immersion or concentration in study-related work tasks. The second dimension, dedication, is about student's perception of whether they consider their work as significant and meaningful. Finally, the third dimension, vigor, reflects a student's level of inspiration, stimulation and positive energy in study-related work tasks. Consequently, absorption, dedication and vigor embrace three essential aspects that in its totality reflects student's magnitude or "vectored energy" (Atman, 1987, p. 15) of engagement in studyrelated work tasks.

Gruman and Saks (2011) suggest, referring to numerous researchers, that employee engagement in organizations is essential and considered it as a "key driver of [...] performance" (p. 125). Equivalent to what is well supported in previous research in organizations, revealing the criticality of employees' engagement for employee work performance, it is assumed in this study that level of study engagement is also a "key" to students' academic performance. As visualized in Figure 1, it is also expected that study engagement is linked to (the environmental factor) supportive study climate. It is supposed that when students experience and perceive their study climate as supportive this would positively stimulate and drive the level of growth of study engagement. Furthermore, when the study engagement increases this also should positively promote an increase in the academic performance of students. This chain of linkages or responses is in line with Luthans et al. (2008) maintaining: "supportive context are needed [...] to achieve [...] growth and performance" (p. 224). Consequently, based on this reasoning, study engagement should act as a mediator in the relationship between supportive study climate and academic performance. The role of study engagement is summarized in this hypothesis:

H3. Study engagement mediates the relationship between supportive study climate and academic performance. 
Furthermore, in this study, it is also assumed that study engagement mediates the relationship between positive emotions and academic performance. In the previous hypothesis, it was discussed how the input of the environmental factors (referring to supportive study climate) that are outside or external to the components of mind in Figure 1 is a starting point and a trigger factor to study engagement and academic performance. In contrast to this, the emphasis in the next hypothesis focuses on how positive emotions, which are situated inside or internal to students themselves as a part of their components of mind, are a trigger to study engagement and academic performance. Specifically, it is about whether (the affect component) positive emotions are linked to (the conative component) study engagement and this latter linkage to academic performance. Within the domain of psychology, it is well known that emotions can cause a variety of different types of responses (such as cognitive, behavioral and conative responses) depending on the type and arousal-strength of emotions (Slåtten, 2011 for some examples). Positive emotions are, as mentioned in the discussion of the first hypothesis, assumed to be positively linked to academic performance, which is a behavioral response. Based on ideas within positive psychology and specifically the broaden-and-build theory of positive emotions (Fredrickson, 2001) it is assumed that positive emotions are also linked to study engagement. Study engagement is, as a conative component of mind, about students' intentional use of their energy and effort in the "work" process of being a student. Thus, study engagement is about students' "devotion" to learning and acquiring knowledge. Accordingly, it relates to fundamental and necessary parts of processes for achieving academic performance. Consequently, there are good reasons to assume study engagement to possess a primary role, or more especially, have a mediating role in the relationship between positive emotions and academic performance. Based on this, the following hypothesis is proposed:

H4. Study engagement mediates the relationship between positive emotions and academic performance.

Psychological capital (PsyCap). PsyCap in Figure 1 is a cognitive component of mind. Cognition is about "the process of coming to know and understand" (Huitt and Cain, 2005, p. 1). Consequently, the PsyCap of a person is a consciousness or cognizance about "who you are" (Luthans et al., 2004, p. 46). PsyCap, originating from positive psychology, focuses on internal strengths and positive resources an individual possesses that can be capitalized or exploited. The resources of PsyCap can be labeled HERO (Luthans and Youssef-Morgan, 2017), which is a contraction for a total of four first-order positive psychological state-like resources, hope, self-efficacy, resilience and optimism (Luthans et al., 2007a, 2007b). Based on this, PsyCap in this study refers to:

an individual's positive psychological state of development characterized by: (1) having confidence (self-efficacy) to take on and put in the necessary effort to succeed at challenging tasks; (2) making a positive attribution (optimism) about succeeding now and in the future; (3) persevering toward goals and, when necessary, redirecting paths to goals (hope) in order to succeed; and (4) when beset by problems and adversity, sustaining and bouncing back and even beyond (resilience) to attain success (Luthans et al., 2007a, 2007b, p. 3).

The state-like resources of PsyCap are dynamic and will, according to Luthans and YoussefMorgan (2017), "interact synergistically to produce differentiated manifestation over time and across contexts" (p. 343). Consequently, PsyCap is open to being nurtured (Luthans et al., 2004). In this study, it is assumed that when students perceive their study climate as supportive it positively cultivates the growth of the resources embraced by PsyCap. Luthans et al. (2008) describe support as "needed [...] to achieve growth" (p. 224). Furthermore, Li
Supportive study climate and academic performance

591 
IJQSS

13,4

et al. (2014) found in their study of students a positive link between a supportive climate and the level of PsyCap. Furthermore, when PsyCap increases because of a supportive study climate, this should also lead to a positive increase in academic performance. Regarding this latter linkage, several studies have revealed a positive linkage between PsyCap and academic performance (Carmona-Halty et al., 2018; Datu et al., 2018; Ortega-Maldonado and Salanova, 2018; Vanno et al., 2014). However, it is expected that PsyCap is essential in this relationship. More precisely, it is assumed that PsyCap has a mediating role between supportive study climate and academic performance. This brings us to the following hypothesis:

H5. PsyCap mediates the relationship between supportive study climate and academic performance.

The abovementioned hypothesis assumes a positive linkage between a supportive study climate and PsyCap. However, there is also good reason to expect positive emotions to be positively linked to PsyCap. These represent two distinctive "routes" to increase PsyCap. The first "route" (referring to supportive study climate) is about the impact of environmental factors on PsyCap whereas the second "route" is about how the affect component of mind (referring to positive emotions) can enable growth in PsyCap that refers to the cognitive component of mind. The broaden-and-build theory of positive emotions supports the idea of a linkage between positive emotions and the cognitive component of mind (Fredrickson, 2001). For example, Fredrickson and Joiner (2002) state: "positive emotions broaden [...] cognition" (p. 172). Similarly, CarmonaHalty et al. (2018) state, referring to both the broaden-and-build theory of positive emotions and previous research: "by experiencing positive emotions, people will enhance their personal resources” (p. 3). In their study, the authors also found empirical support for such a positive relationship between positive emotions and PsyCap of students. In line with this, it is also expected in this study to find positive emotions as a source that facilitates an increase in PsyCap. Consequently, the following hypothesis is suggested:

H6. The higher the degree of positive emotions, the greater the level of PsyCap.

In H5, it was maintained that PsyCap is directly linked to academic performance. This is well supported in previous research (Carmona-Halty et al., 2018; Datu et al., 2018; OrtegaMaldonado and Salanova, 2018; Vanno et al., 2014). However, it is also reasonable to assume the relationship between PsyCap and academic performance to be mediated by study engagement. Specifically, as visualized in Figure 1, this chain of linkages is about how the cognitive component of mind (referring to PsyCap) is linked to the conative component of mind (referring to study engagement) and how the conative component of mind is linked to behavioral output (referring to academic performance). Study engagement, as a conative component of mind, was referred to in the previous discussion as students' intentional use or their "vectored energy" (Atman, 1987, p. 15) in the "work" of being a student. Consequently, it is reasonable to assume study engagement to have a vital role in the process of learning and hence is linked to academic performance. Previous research has supported well a linkage between PsyCap and the level of engagement of individuals both within educational contexts (Datu and Valdez, 2016; Siu et al., 2014) as well as in organizational contexts (Chen, 2015; Joo et al., 2016). Consequently, when study engagement increases, because of positive development in PsyCap, this should lead to an increase in academic 
performance. This role of study engagement can be summarized in the following hypothesis:

H7. The relationship between PsyCap and academic performance is mediated by study engagement

The final suggested relationship in this study assumes that PsyCap mediates the relationship between positive emotions and academic performance. As such, it embraces aspects discussed in both $H 5$ and $H 6$. Specifically, $H 6$ proposed positive emotions to be related to PsyCap. Moreover, in H5, PsyCap is assumed to be related to academic performance. When taken together and based on the broaden-and-build theory of positive emotions, it is anticipated that positive emotions are an enabler factor or fostering variable to those resources included in PsyCap. Furthermore, an increase in PsyCap, because of an increase in positive emotions, should lead to a positive increase in academic performance. Previous research supports this pattern of linkages. For example, Carmona-Halty et al. (2018) state: "study-related positive emotions may facilitate the building of PsyCap, and in turn, these 'resource caravans' [referring to the four resources of PsyCap] would foster academic performance” (p. 5). In their study undertaken among 639 Chilean high school students, the authors also found support for their assumption that PsyCap is a (full) mediator in the relationship between study-related emotions and academic performance. Based on both the broaden-and-build theory of positive emotions and previous research by CarmonaHalty et al. (2018), it is expected to find PsyCap to mediate the relationship between positive emotions and academic performance. This brings us to the final hypothesis, which proposes:

H8. PsyCap mediates the relationship between positive emotions and academic performance.

\section{Data}

\section{Questionnaire}

Items included in the questionnaire were developed in line with theoretical foundations and relevant literature recommendations. To best fit the aim and focus, several items were adapted for this specific study. Items for PsyCap were based on Luthans et al. (2007b), those for study engagement were based on Schaufeli et al. (2002b), and those for academic performance were based on Vanno et al. (2014). Items used to capture students' perceptions of a supportive study climate were developed specifically for this study. These items captured three aspects:

(1) teacher-student relationships;

(2) peer-student relationships; and

(3) students' use of support resources.

Items for positive emotions were based on Diener et al. (2010). All measures were anchored on a five-point Likert scale from (1) strongly disagree to (5) strongly agree. A face validity check of the questionnaire was conducted. Moreover, the questionnaire was pretested on the target group of respondents as well as on experts from academia. This resulted in some minor modifications. Table 1 shows the complete list of all items and the reliability for each construct.
Supportive study climate and academic performance 


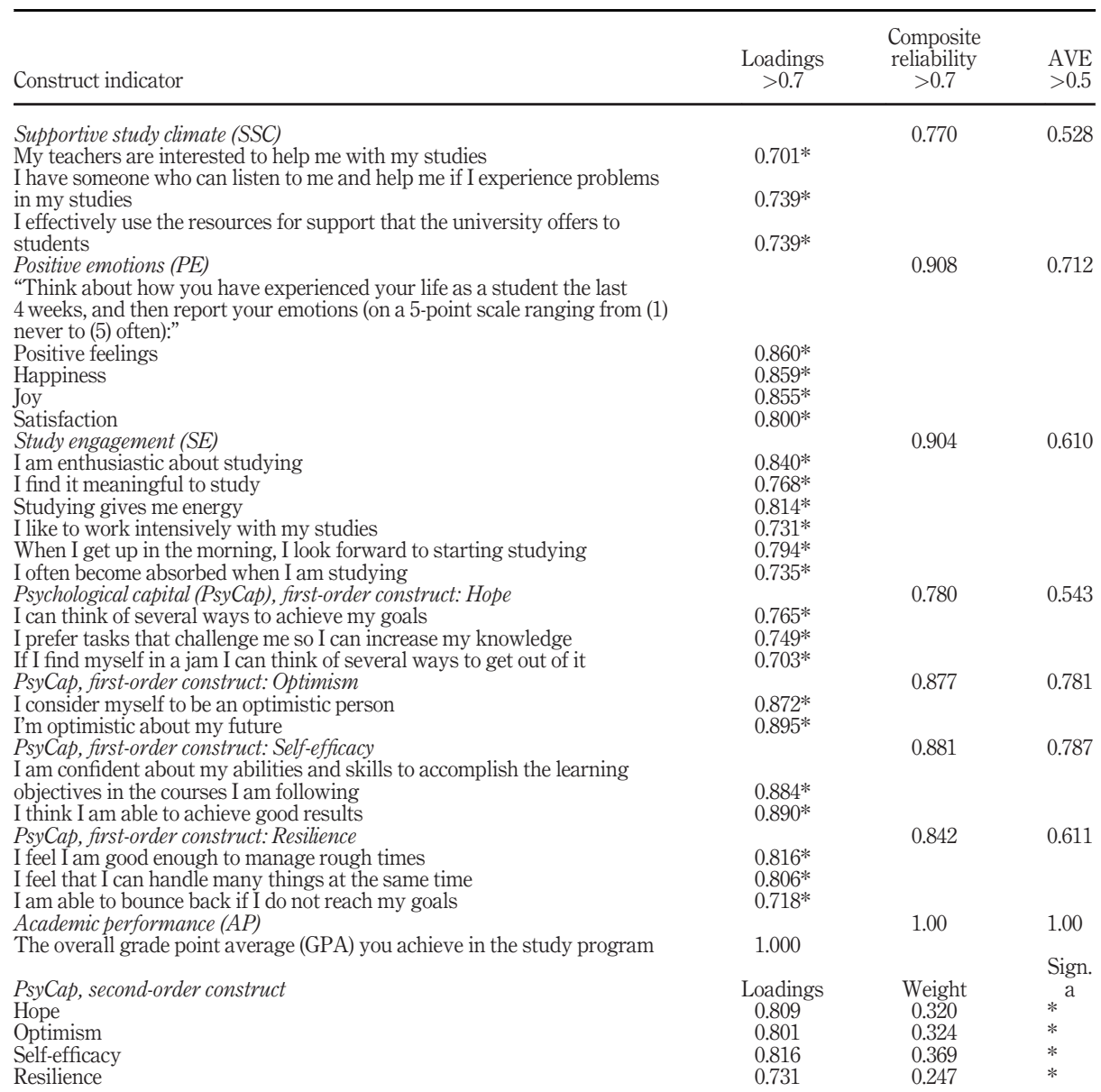

Table 1.

Measurement model results

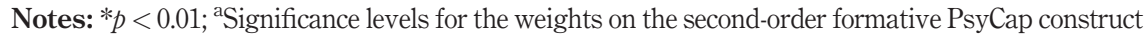

\section{Sample characteristics}

A total of 588 bachelor students agreed to participate in the survey. $76 \%$ of the respondents were females. The average age was 26 years. $34 \%$ of the participants were first-year bachelor students, $25 \%$ in the second year and $41 \%$ in the third and last year of the bachelor study. $31 \%$ studied bachelor in education, $16 \%$ studied bachelor in nursing and health studies, $16 \%$ in business administration, $12 \%$ in psychology, while the last $25 \%$ studied sports sciences, law, tourism and service management.

\section{Analysis and results \\ Method}

Partial least squares (PLS)-based structural equation modeling (SEM) was used to test the conceptual models and the hypothesized relationships, using the software SmartPLS (Ringle 
et al., 2015). PLS results were evaluated in two steps, first evaluation of the quality of the measurement model in each dimension, and second, evaluation of the quality of the structural model. In addition, based on the structural model results, mediating effects were estimated and analyzed. The constructs supportive study climate, positive emotions and study engagements were modeled as first-order reflective measurement models. The construct PsyCap was modeled as a second-order reflective-formative model and estimated with a two-stage approach (Becker et al., 2015; Hair et al., 2018). Academic performance was modeled as a single-item measure. We followed "the rules of thumb" by Hair et al. (2014, 2018) when assessing the quality of the measurement and structural model results.

\section{Measurement model}

The first-order reflective constructs supportive study climate, positive emotion and study engagement all had item loadings above 0.7, indicating item reliability (Table 1). Further, the same first-order constructs had composite reliability values that exceeded the suggested rule of thumb by Hair et al. (2014) of 0.7, indicating reliability. The average variance extracted (AVE) for the three constructs exceeded the suggested rule of thumb of 0.5 , indicating convergent validity. A construct should be distinct from the other constructs, and examination of both the cross-loadings and the Fornell-Larcker criterion (Hair et al., 2014) indicated discriminant validity.

For the second-order reflective-formative construct PsyCap, the first-order constructs (hope, optimism, self-efficacy, resilience) are modeled as reflective (as commented above), while the second-order construct (PsyCap) is modeled as formative. The first-order reflective constructs, as part of the second-order reflective-formative construct, satisfied the rules of thumb regarding item loadings, composite reliability, AVE (Table 1) and discriminant validity. For the second-order formative construct of PsyCap, no multicollinearity problems for the lower-order constructs existed (all variance inflation factors below 2). The construct weights on PsyCap were 0.32 for hope and optimism, 0.37 for self-efficacy and 0.25 for resilience, and all were statistically significant, indicating the appropriateness of the secondorder construct.

\section{Structural model}

The direct effects in the structural model are shown in Figure 2. We did not find any significant relationship between supportive study climate and academic performance, and thus no support for $H 1$. There was no statistically significant relationship between positive emotions and academic performance. All other direct effects were statistically significant and positive. $H 6$ received strong support, the standardized path coefficient between positive emotions and PsyCap was 0.50 .

The mediator effects results are presented in Table 2. The conceptual model is a complex model, with a range of relationships. Because of that, the results reported in Table 2 are specific for individual mediator effects, and not total or overall mediator effects (as are those based on all possible paths between investigated constructs). H2, that the relationship between supportive study climate and academic performance would be mediated through positive emotions, was not supported. We obtained support for $H 3$ and $H 5$. That means the relationship between supportive study climate and academic performance would be fully mediated by both study engagement and PsyCap. Further, $H 4$ and $H 8$ were supported, implying that the relationship between positive emotions and academic performance would be partially mediated by both study engagement and PsyCap. Finally, $H 7$ was supported. It shows that study engagement partially mediated the relationship between PsyCap and academic performance.
Supportive study climate and academic performance 


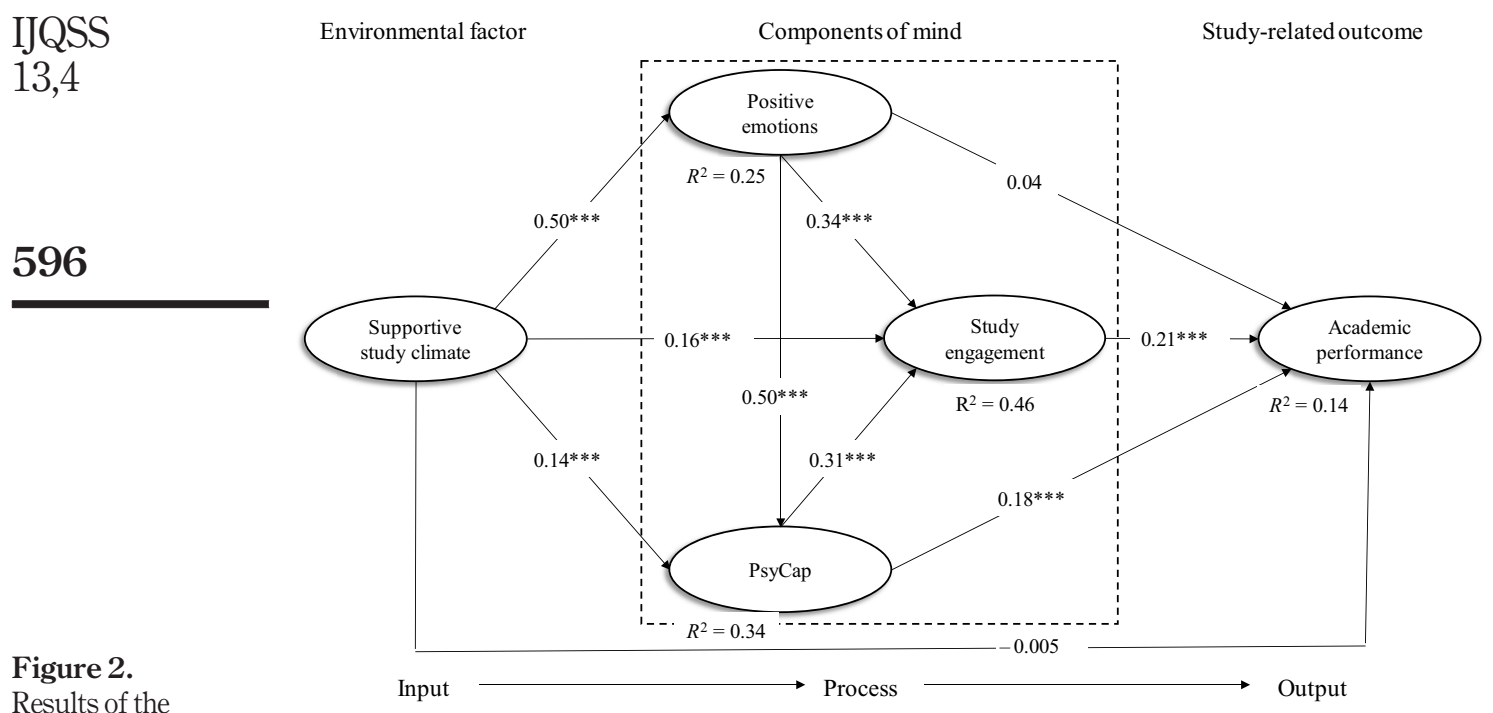

structural model

Note: Standardized coefficients $(* * * p<0.01)$

\begin{tabular}{lllcccl}
\hline Hypothesis & Effect $^{\mathrm{a}}$ & Mediator $^{\mathrm{a}}$ & $\begin{array}{c}\text { Specific } \\
\text { total effect }\end{array}$ & $\begin{array}{c}\text { Specific } \\
\text { indirect effectb }\end{array}$ & VAFc & $\begin{array}{l}\text { Specific } \\
\text { mediator effectd }\end{array}$ \\
\hline$H 1$ & SSC $\rightarrow$ AP & PE & -0.005 & & & \\
$H 2$ & SSC $\rightarrow$ AP & PE & 0.015 & 0.019 & & N.S. \\
$H 3$ & SSC $\rightarrow$ AP & SE & 0.111 & $0.034^{* * *}$ & 1.17 & Full \\
$H 4$ & PE $\rightarrow$ AP & SE & $0.072^{* * *}$ & 0.65 & Partial \\
$H 5$ & SSC $\rightarrow$ AP & PsyCap & 0.021 & $0.026^{* *}$ & 1.24 & Full \\
$H 6$ & PE $\rightarrow$ PsyCap & & $0.502^{* * *}$ & & & \\
$H 7$ & PsyCap $\rightarrow$ AP & SE & 0.247 & $0.065^{* * *}$ & 0.26 & Partial \\
$H 8$ & PE $\rightarrow$ AP & PsyCap & 0.130 & $0.091^{* * *}$ & 0.70 & Partial
\end{tabular}

Notes: a Supportive study climate (SSC), Academic performance (AP), Positive emotions (PE), Study engagement (SE), Psychological capital (PsyCap); ${ }^{\text {b** }} p<0.05 ; * * * p<0.01$ are significance levels, ${ }^{\mathrm{C}} \mathrm{VAF}$ (variation accounted for) is the size of the specific indirect effect in relation to the specific total effect, ${ }^{\mathrm{d}}$ Almost no mediation effect when VAF was less than 0.20; VAF larger than 0.20 and less than 0.80 can be

Table 2. characterized as partial mediation; and VAF equal to and above 0.80 can be assumed to be full mediation Hypothesis results (Hair et al., 2014). N.S. = not significant and cannot then say anything about mediator effects

In addition to looking at specific or individual effects, we also considered the total effects and overall mediator effects (these are not reported in tables). The total effects on academic performance were for positive emotions $0.234(\phi<0.01)$, for study engagement 0.21 $(p<0.01)$ and for PsyCap $0.247(p<0.01)$. In other words, the "components of mind" significantly influenced academic performance.

Total or overall indirect effect of positive emotions, study engagement and PsyCap (i.e. the components of mind jointly) on the relationship between supportive study climate and academic performance was $0.185(p<0.01)$. Because the direct effect was almost zero (- 
0.005), we found that the three "components of mind" fully mediated the relationship between supportive study climate and academic performance.

\section{Discussion}

As mentioned explicitly in the introduction part this paper responds to the call for more research on the association between social factors, PsyCap and academic performance mentioned in Carmona-Halty et al. (2019). Additionally, it contributes to Ortega-Maldonado and Salanova's (2018) call for more research, stating: “deeper research on this field [referring to academic performance] is necessary to develop evidence-based interventions to improve students' performance" (p. 390). Consequently, it broadens and deepens previous research substantially. In the following four main contributions of this study are discussed.

First, Datu et al. (2018) state regarding PsyCap: "little is known about the precise mechanism that can potentially explain why PsyCap may be linked to students' academic functioning" (p. 261). However, this study responds to this knowledge gap by examining several potential patterns of how PsyCap is linked to academic performance. It reveals that PsyCap has multiple roles. It was found that PsyCap is directly related to academic performance as well as to the process of study engagement, which is associated with academic performance. Furthermore, PsyCap was also found to be a mediator between supportive study climate, positive emotions and academic performance. These (total four) multiple effects of PsyCap highlight the key role of PsyCap for academic achievement. No previous study undertaken has examined such numerous effects of PsyCap on academic performance as done in this study. Consequently, it contributes to a more nuanced knowledge and insight in what way PsyCap, as a cognitive component of mind, is linked to academic performance.

Second, this study also reveals the critical role of students' engagement because it actually has slightly stronger (direct) effect on academic performance in comparison to PsyCap $(\beta=0.21$ versus $\beta=0.18)$. In addition, its critical role is also highlighted because it was found to be a mediator between positive emotions, supportive study climate and PsyCap and academic performance. This is the first study that simultaneously examines these multiple relationships associated with study engagement in the same study. As such, it responds to the call for more research regarding this knowledge gap proposed by Carmona-Halty et al. (2018). In their study, the authors suggest: "it would be important to add other meaningful constructs such as school engagement" (p. 9). This study empirically demonstrates that study engagement, as a conative component of mind, is both a meaningful and powerful construct for higher education institutions to focus on when seeking out potential ways to improve the academic performance of their students.

Third, this study reveals that positive emotions matter because they have an impact on academic performance. However, positive emotions do not have a direct effect on academic performance. As this study reveals, no significant relationships were found between the two concepts. This (nonsignificant) finding is similar to the findings in the study by CarmonaHalty et al. (2018). On the other hand, the mechanisms of positive emotions function as enablers to directly increase both study engagement $(\beta=0.34)$ and PsyCap $(\beta=0.50)$. In addition, the relationship between positive emotions and academic performance is also mediated through study engagement and PsyCap. To the authors' knowledge, only one previous study, that is Carmona-Halty et al. (2018), has examined the relationship between positive emotions and PsyCap in an academic setting. Similar to the findings in CarmonaHalty et al. (2018), this study found strong support for a linkage between positive emotions and PsyCap. However, this study extends the study by Carmona-Halty et al. (2018) by also investigating the direct and indirect effects of positive emotions on study engagement and
Supportive study climate and academic performance 
IJQSS

13,4

its relationship with academic performance. Clearly, positive emotions, as an affective component of mind, are an influential factor to improve students' academic performance.

Fourth, Ortega-Maldonado and Salanova (2018) recently noted: "it would be important that future research also include designing and testing interventions on PsyCap" (p. 399). Similarly, Carmona-Halty et al. (2018) commented that there has been: "scarce research about antecedents to PsyCap in academic settings" (p. 9). However, this study responds to this recommendation and knowledge gap in previous research. Specifically, it contributes by examining how a supportive study climate acts as an intervention variable on PsyCap. However, it is not limited to only examining interventions on PsyCap. It also examines how a supportive study climate acts as an intervention variable on both PsyCap, positive emotions, study engagement and their role in academic performance. The findings from the empirical study are clear. There is a no significant linkage between supportive study climate and academic performance. As such this study support the study of Carmona-Halty et al. (2019) revealing that teacher-students (as one aspect of a supportive study climate) is not directly linked to academic performance but is mediated through PsyCap. In contrast, this study points to how a supportive study climate (when it is perceived as positive) is a direct driver to positive emotions $(\beta=0.50)$, study engagement $(\beta=0.16)$ and PsyCap $(\beta=0.14)$. Furthermore, the relationship between supportive study climate and academic performance is mediated through the three components of mind. In summary, these findings point out two main contributions from this study. First, it is clear that the three components of mind, PsyCap, positive emotions and study engagement, all have a central role for academic performance. Second, all three components of mind are dynamic, implying that they are manageable or changeable through the development of an appropriate and "well-designed" supportive study climate. This latter aspect has several interesting and important managerial implications for higher education institutions regarding how to improve the academic performance among their students.

\section{Conclusions}

This paper focused on factors associated with the academic performance of university students. It extends previous research showing how the three components of mind, PsyCap, positive emotions and study engagement, have mediating roles between supportive study climate and academic performance. It also reveals the existence of a complex, or more precisely, a multifaceted pattern among PsyCap, positive emotions and study engagement that promotes academic performance. It also shows that the three components of mind are manageable through a supportive study climate. This study is limited to only examining the concept of supportive study climate at an overall level. Future research should explore how specific subdimensions of supportive study climate (e.g. peer support versus academic support) is linked to PsyCap, positive emotions, study engagement and academic performance. Such an approach, among numerous other potential future research opportunities, would contribute to making progress in our understanding and insight of factors associated with academic performance among university students.

\section{References}

Atman, K. (1987), "The role of conation (striving) in the distance learning enterprise”, American Journal of Distance Education, Vol. 1 No. 1, pp. 14-28.

Bakker, A.B., Albrecht, S.L. and Leiter, M.P. (2011), "Key questions regarding work engagement", European Journal of Work and Organizational Psychology, Vol. 20 No. 1, pp. 4-28.

Bakker, A.B., Schaufeli, W.B., Leither, M.P. and Taris, T.W. (2008), "Work engagement: an emerging concept in occupational health psychology", Work and Stress, Vol. 22 No. 3, pp. 187-200. 
Becker, J.-M., Klein, K. and Wetzels, M. (2015), "Hierarchical latent variable models in PLS-SEM: guidelines for using reflective-formative type models", Long Range Planning, Vol. 45 Nos 5/6, pp. 359-394.

Carmona-Halty, M., Salanova, M., Liorens, S. and Schaufeli, W.B. (2018), "How psychological capital mediates between study-related positive emotions and academic performance", Journal of Happiness Studies, Vol. 20 No. 2, pp. 605-617.

Carmona-Halty, M., Schaufeli, W.B. and Salanova, M. (2019), "Good relationships, good performance: the mediating role of psychological capital - a three-wave study among students", Frontiers in Psychology, Vol. 10, pp. 1-14.

Chen, S.L. (2015), "The relationship of leader psychological capital and follower psychological job engagement and job performance: a multilevel mediating perspective", The International Journal of Human Resource Management, Vol. 26 No. 18, pp. 2349-2365.

Datu, J.A.D. and Valdez, J.P.M. (2016), "Psychological capital predicts academic engagement and wellbeing in Filipino high school students", The Asia-Pacific Education Researcher, Vol. 25 No. 3, pp. 399-405.

Datu, J.A.D., King, R.B. and Valdez, J.P.M. (2018), "Psychological capital bolsters motivation, engagement, and achievement: cross-sectional and longitudinal studies", The Journal of Positive Psychology, Vol. 13 No. 3, pp. 260-270.

Diener, E., Wirtz, D., Tov, W., Kim-Prieto, C., Choi, D-W., Oishi, S. and Biswas-Diener, R. (2010), "New well-being measures: short scales to assess flourishing and positive and negative feelings", Social Indicators Research, Vol. 97 No. 2, pp. 143-156.

Fineman, S. (2003), Understanding Emotion at Work, Sage Publications, London.

Fredrickson, B.L. (2001), "The role of positive emotions in positive psychology: the broaden-and-build theory of positive emotions", American Psychologist, Vol. 56 No. 3, pp. 218-226.

Fredrickson, B.L. and Joiner, T. (2002), "Positive emotions trigger upward spirals toward emotional well-being”, Psychological Science, Vol. 13 No. 2, pp. 172-175.

Gruman, J.A. and Saks, A.M. (2011), "Performance management and employee engagement", Human Resource Management Review, Vol. 21 No. 2, pp. 123-136.

Hair, J.F., Jr, Hult, G.T.M., Ringle, C.M., and Sarstedt, M. (2014), A Primer on Partial Least Squares Structural Equation Modeling (PLS-SEM), SAGE, London.

Hair, J.F., Jr, Sarstedt, M., Ringle, C.M., and Gudergan, S.P. (2018), Advanced Issues in Partial Least Squares Structural Equation Modeling, SAGE, London.

Huitt, W. and Cain, S. (2005), "An overview of the conative domain", Educational Psychology Interactive, pp. 1-20, Valdosta State University, Valdosta, GA, available at: www. edpsycinteractive.org/brilstar/chapters/conative.pdf (accessed 22 January 2019)

Joo, K.B., Lim, D.H. and Kim, S. (2016), "Enhancing work engagement - the role of psychological capital, authentic leadership, and work empowerment", Leadership and Organization Development Journal, Vol. 37 No. 8, pp. 1117-1134.

Lazarus, R.S. (1991), Emotion and Adaptation, Oxford University Press, New York, NY.

Li, B., Yu, F. and Zhou, Z. (2014), "Positive psychological capital: a new approach to social support and subjective well-being”, Social Behavior and Personality: An International Journal, Vol. 42 No. 1, pp. 135-144.

Luthans, F. and Youssef-Morgan, C.M. (2017), "Psychological capital: an evidence-based positive approach", The Annual Review of Organizational Psychology and Organizational Behavior, Vol. 4 No. 1, pp. 339-366.

Luthans, F., Luthans, K.W. and Luthans, B.C. (2004), "Positive psychological capital: beyond human and social Capital", Business Horizons, Vol. 47 No. 1, pp. 45-50.

Luthans, F., Youssef-Morgan, C.M., and Avolio, B.J. (2007a), Psychological Capital: Developing the Human Competitive Edge, Oxford University Press, Oxford.
Supportive study climate and academic performance 
IJQSS

13,4

600

Luthans, F., Avolio, B.J., Avey, J.B. and Norman, S.M. (2007b), "Positive psychological capital: measurement and relationship with performance and satisfaction", Personnel Psychology, Vol. 60 No. 3, pp. 541-572.

Luthans, F., Norman, S.M., Avolio, B.J. and Avey, J.B. (2008), "The mediating role of psychological capital in the supportive organizational climate - employee performance relationship", Journal of Organizational Behavior, Vol. 29 No. 2, pp. 219-238.

Ortega-Maldonado, A. and Salanova, S. (2018), "Psychological capital and performance among undergraduate students: the role of meaning-focused coping and satisfaction", Teaching in Higher Education, Vol. 23 No. 3, pp. 390-402.

Peter, J.P. and Olson, J.C. (1996), Consumer Behavior and Marketing Strategy, IRWIN, Company.

Ringle, C.M. Wende, S. and Becker, J.-M. (2015), "SmartPLS 3", SmartPLS GmbH, Boenningstedt, available at: www.smartpls.com

Salanova, M., Schaufeli, W.B., Martinez, I.M. and Breso, E. (2010), "How obstacles and facilitators predict academic performance: the mediation role of study burnout and engagement", Anxiety, Stress and Coping, Vol. 23 No. 1, pp. 53-70.

Schaufeli, W.B., Martinez, I.M., Pinto, A.M., Salanova, M. and Bakker, A. (2002a), "Burnout and engagement in university students - a cross-national study", Journal of Cross-Cultural Psychology, Vol. 33 No. 5, pp. 464-481.

Schaufeli, W.B., Salanova, M., González-Romá, V. and Bakker, A.B. (2002b), “The measurement of engagement and burnout: a two-sample confirmatory factor-analytic approach", Journal of Happiness Studies, Vol. 3 No. 1, pp. 71-92.

Siu, O.L., Bakker, A.B. and Jiang, X. (2014), "Psychological capital among university students: relationships with study engagement and intrinsic motivation", Journal of Happiness Studies, Vol. 15 No. 4, pp. 979-994.

Slåtten, T. (2011), "Emotions in service encounters from the perspectives of employees and customers", Dissertation, Karlstad University. Universitetstrykkeriet, Karlstad.

Vanno, V., Kaemkate, W. and Wongwanich, S. (2014), "Relationships between academic performance, perceived group psychological capital, and positive psychological capital of Thai undergraduate students", Procedia - Social and Behavioral Sciences, Vol. 116, pp. 3226-3230.

Villavicencio, T.F. and Bernardo, A.B.I. (2013), "Negative emotions moderate the relationship between selfefficacy and achievement of Filipino students", Psychological Studies, Vol. 58 No. 3, pp. 225-232.

Wentzel, K.R., Battle, A., Russell, S.L. and Looney, L.B. (2010), "Social support from teachers and peers as predictors of academic and social motivation”, Contemporary Educational Psychology, Vol. 35 No. 3, pp. 193-202.

Zhou, J. and Shalley, C.E. (2008), Handbook of Organizational Creativity, Lawrence-Erlbaum, New York, NY.

\section{Further reading}

You, J.W. (2016), “The relationship among college students' psychological capital, learning empowerment, and engagement", Learning and Individual Differences, Vol. 49, pp. 17-24.

\section{Corresponding author}

Terje Slåtten can be contacted at: Terje.slatten@inn.no

For instructions on how to order reprints of this article, please visit our website:

www.emeraldgrouppublishing.com/licensing/reprints.htm

Or contact us for further details: permissions@emeraldinsight.com 